\title{
How to Write Publishable Qualitative Research
}

\author{
Kerstin Stenius, Klaus Mäkelä, Michal Miovský and \\ Roman Gabrhelík
}

\section{Introduction}

Conducting and publishing qualitative research requires the same principal skills as quantitative research. In addition, there may be special challenges for qualitative researchers. They may have to overcome prejudice and communication barriers within the scientific community. This chapter provides advice to authors who wish to publish their research in a scientific journal. The chapter starts with some remarks on the special characteristics of the processes of qualitative study that can affect the reporting of the results. It then identifies the common criteria for good qualitative research and presents some evaluation principles used by editors and referees. Finally, it offers practical advice for writing and publishing a qualitative scientific article.

In quantitative research, the observations typically follow a systematic scheme whereby the classification of the observations is already determined to a large extent when the data collection starts. This makes it possible to gather large data sets for numerical analyses, but the understanding of the findings will be restricted by the concepts on which the collection of data was based. One can argue that in qualitative research, in which the observations (e.g., texts, sounds, behaviour, images) are usually fewer, the researcher's preconception of a social phenomenon does not determine the research results to the same extent as in quantitative research (Sulkunen, 1987) Qualitative research thus is often used

\section{How to cite this book chapter:}

Stenius, K, Mäkelä, K, Miovský, M and Gabrhelík, R. 2017. How to Write Publishable Qualitative Research. In: Babor, T F, Stenius, K, Pates, R, Miovský, M, O’Reilly, J and Candon, P. (eds.) Publishing Addiction Science: A Guide for the Perplexed, Pp. 155-172. London: Ubiquity Press. DOI: https://doi.org/10.5334/bbd.h. License: CC-BY 4.0. 
to study social processes or the reasons behind human behaviour (Sulkunen, 1987), or as Wikipedia puts it: The why and how of social matters more than the what, where, and when that are often central to quantitative research.

Qualitative addiction research focuses on topics that range from historical processes to treatment outcomes. Qualitative research is used increasingly to answer questions about alcohol and other drug policy, including rapid assessment of policy developments (e.g., see Stimson et al., 2006). It is used to study program implementation and to evaluate various policy measures (e.g., see Miovský, 2007; Miovský \& Zábranský, 2003). Furthermore, ethnographers have used qualitative methods to increase the understanding of patterns of substance use in various population groups (e.g., see Lalander, 2003).

There is also an important and growing interest in combining qualitative and quantitative research into so-called mixed-methods research, notably within evaluation and intervention research in the clinical and policy fields (Creswell \& Plano Clark, 2007). The combination of qualitative and quantitative methods can deepen the understanding of processes, attitudes, and motives. There is frequent discussion in theoretical mixed-method studies of the relations between various kinds of knowledge and the actual procedure of combining qualitative and quantitative methods (Creswell \& Tashakkori, 2007). Box 8.1 presents criteria for good mixed methods articles.

Despite what we believe is an increasing interest in qualitative research, many journals do not publish qualitative studies. In addition, many editors of addiction journals have noted that qualitative manuscripts are more likely to present the editors with problems and are more often declined for publication than are quantitative research reports. Some of the problems are related to how the articles are written.

In the addiction field, there is no journal dedicated exclusively to qualitative research, and in many journals articles must follow a strict standard format. Qualitative articles tend to break with that format, putting special demands

a) The study has two sizeable data sets (one quantitative, one qualitative), with rigorous data collection and appropriate analyses, and with inferences made from both parts of the study.

b) The article integrates the two parts of the study, in terms of comparing, contrasting, or embedding conclusions from both the qualitative and the quantitative strands.

c) The article has mixed-methods components that can enrich the newly emerging literature on mixed methods research.

Box 8.1: Criteria for good mixed-methods articles.

Source: Creswell and Tashakkori (2007). 
on the reader. Another problem for a comparatively small research field such as addiction research is that it is difficult to find referees who are competent to evaluate qualitative methods and analyses. A qualitative article thus runs the risk of being reviewed by someone who not only is unqualified but also may be prejudiced against qualitative research. For all of these reasons, qualitative researchers have to be particularly professional in their writing.

\section{The Challenges of Publishing Qualitative Research}

Qualitative methods can be used for pilot studies, to illustrate the results of statistical analysis, in mixed-methods studies, and in independent qualitative research projects (c.f. Denzin \& Lincoln, 1998). This chapter will focus on the last category: original research reports that use qualitative methods. We will emphasise the similarities and considerable overlap in the evaluation, and effective presentation, of both qualitative and quantitative research.

The first and foremost aim of all social research, quantitative as well as qualitative, is to present a conceptually adequate description of a historically specific topic, subject, or target. In qualitative research, the determination of the subject is as important as the choice of a population in a statistical study. The description of the subject is always, in both types of study, a theoretical task because it requires a conceptually well-organised analysis.

The processes of classification, deduction, and interpretation are in their fundamental aspects similar for both qualitative and quantitative research. Quantitative analyzing operations, however, are more clear-cut than qualitative operations. Furthermore, the various steps of quantitative research can be more clearly distinguished than can those of a qualitative study. The first issue is that, in qualitative work, the collection and processing of data are more closely intertwined than in a quantitative study. Especially when the researchers personally collect the data, they will not be able to avoid problems of interpretation during the collection phase. A specific issue in some qualitative research is that the methods used can change during the study, depending on interim results. It is a challenge to explain in a short article why this has happened, and why one has used a different method in the final phase of the data acquisition than in the previous parts; or why one changed a classification scheme and encoded the data in a different manner. The researchers must also carefully consider their relations with the study objects. Many qualitative reports discuss at length the character and psychology of the process of data collection, but are less careful in describing what happened to the interview tapes afterwards. Were they transcribed in whole or in part, how was the resulting stack of papers handled and sorted out? In qualitative research, these data processing explications may be necessary to render credibility to the analysis.

A second issue is that qualitative analysis is not restricted to an unambiguously demarcated data set in the same way that a quantitative study is. Good 
researchers may keep a detailed field diary and make notes of all discussions and thus produce a corpus to which they limit their analysis. Nevertheless, during the analysis phase, they may recall an important detail that they had not recorded in their notes but must take into account in the analysis. The qualitative researchers have to describe this analytical process in an honest and convincing way.

There are several basic factors that make the publication of qualitative research harder and different from standard journal article models of quantitative research (Miovský, 2006):

- The research design may be less strictly defined from the beginning of the research project, and it is not unusual to have design changes as new questions arise and new findings are considered. Redesigning necessitates an especially thorough and sometimes lengthy methodology section to explain those changes.

- Qualitative research uses many different theoretical frames (phenomenology, constructivistic approaches, hermeneutics, etc.) that affect data selection, methodology, and presentation. This variance is also to some extent found within quantitative research. But because analysis and reporting are more closely intertwined in qualitative research, the differences in theoretical perspectives become even more important. As an author, you will have to argue even more clearly for the choice and sufficiency of your data and their scientific significance.

- Compared with quantitative research, qualitative research uses different concepts of research validity (e.g., credibility), with different theoretical backgrounds (Whittemore, Chase \& Mandle, 2001) and different views on correct sampling methods and the representativeness of data (Patton, 1990). Some sampling strategies combine qualitative and quantitative perspectives (e.g., respondent-driven sampling). Qualitative-oriented research can be performed with a single case study but also with sampling methods such as snowball sampling or respondent-driven sampling, which can combine traditional probability sampling methods with qualitative-oriented methods. It can be a challenge to describe these data sets and the data collecting methods, as well as why and how they were used, within the length limits usually applied to research reports.

All these factors present authors with a set of practical difficulties, not only because of technical page limits but also because there are not many reviewers with insight into qualitative methods and analysis. Scientific publishing has also gradually become more streamlined, with a lot of written and unwritten habits and rules that are usually based on quantitative approaches and methods. A qualitative researcher must be prepared to tackle these obstacles. 


\section{Evaluation Criteria for Qualitative Analysis}

There are some differences between the evaluation of qualitative and quantitative research. The replicability of a qualitative study cannot be formulated as a problem of reliability, and the accuracy of a qualitative interpretation cannot be compared with the explanatory power of a statistical model. In the following paragraphs, we propose three main criteria for evaluating qualitative studies: 1) significance of the data set and its social or cultural place; 2) sufficiency of the data and coverage of the analysis; and 3) transparency and repeatability of the analysis. Since in qualitative research the analyses and reporting are very closely intertwined, these criteria are as relevant to researchers and authors as they are to reviewers and editors.

\section{Significance of the Data Set and its Social or Cultural Place}

The researchers should be prepared to argue that their data are worth analyzing. It is not easy to identify criteria for the significance of data. One precondition can, however, be presented: the researcher should carefully define the social and cultural place (contextualising) and the production conditions of the material.

The production conditions can be discussed at several levels. When the data consist of cultural products, their production and marketing mechanisms should be considered. Texts produced by individuals should be related to their social position. Furthermore, the situational aspect of the data production and the researcher's potential influence on the data should be evaluated. The relationship of cultural products to people's everyday life depends on the production and distribution network. Weekly magazines and movies represent the ambient culture at a number of levels. When doing comparisons over time, it is important to bear in mind that the social and cultural place of one and the same genre may vary from decade to decade.

In international comparisons, it is important to be able to exclude demographic variation as a factor causing differences. If we wish to identify the distinct characteristics of Finnish A.A. members' stories, we should make sure that we do not compare Finnish farmers with American college professors. The criterion for selecting the target group is not demographic but cultural representativeness.

Additionally, people speak of the same things in different ways on different occasions, and it is the task of the researchers to decide which discourse they want to study and argue for their decision in the article. Informal interviews are often advocated instead of questionnaires on the grounds that they will produce more genuine information. But, on the other hand, an in-depth interview is a more exceptional situation for a present-day person than completing 
a questionnaire. Possible effects of the power structures and gender relations present in every social situation should be considered in the discourse analysis, since it could affect the outcomes of the qualitative research.

Study of the variations of discourse, i.e., the incorporation of the production conditions into the study design, can be rather laborious. Members of A.A. emphasize various sides of their story according to the composition of the audience, and depending on whether they talk at a closed or an open A.A. meeting. Furthermore, the life story will change in relation to how long the speaker has been in A.A. Even when variation cannot be incorporated into the actual study design, it is important to consider and discuss the conditions under which the material was produced and their place in the potential situational variation of the discourse.

\section{Sufficiency of Data and Coverage of Analysis}

For statistical studies, we are able to calculate in advance the extent of data needed to estimate the parameters accurately enough for the purpose of the analysis. We have no similar methods for estimating the extent of qualitative data required. We usually speak about data saturation: data collection can be terminated when new cases no longer disclose new features (Strauss \& Corbin, 1998). The difficulty here, of course, is that the limit is not always known in advance, and the collection of data is rarely a continuing process that can be terminated or extended at will.

Only in very special cases can you base your analyses on just a handful of observations. In most cases, you will need to be certain that you cover the variation of the phenomenon you are studying. On the other hand, a loose but useful rule is that one should not collect too much data at a time. It is better to analyze a small data batch carefully first and only then determine what additional data will be needed. To divide the analyses into smaller parts also helps to produce manageable results for a publishable report.

It is often advisable to group the collection of data according to factors which may prove important as production conditions. The goal is not to explain the variation but to make sure that the data are sufficiently varied. For example, it would be helpful to stratify the collection of A.A. members' life stories according to the members' social position, sex, age, and length of sobriety (Arminen, 1998). The only difficulty is that we will have no advance knowledge of which characteristics will decide the type of life stories; the stories may depend more on drinking experiences than on external circumstances, and within A.A. there may be various narrative traditions which have an influence on the life stories.

Proper coverage of the analysis means that the researchers do not base their interpretations on a few arbitrary cases or instances but on a careful reading of the whole material. Qualitative reports are often loosely impressionistic because the excessive amount of material has made it unfeasible to analyze it carefully enough. 


\section{Transparency and Repeatability of the Analysis}

Transparency of the analysis means that the readers are able to follow the researcher's reasoning and that they are given the necessary information for accepting the interpretations-or for challenging them. The repeatability of an analysis means that the rules of classification and interpretation have been presented so clearly that another researcher applying them will reach the same results. We may identify three ways of improving the transparency and repeatability of qualitative analysis and the report: 1) enumerating the data; 2) dividing the process of interpretation into steps; and 3) making explicit the rules of decision and interpretation.

The best method to decrease arbitrariness and increase repeatability is to enumerate all units on which the interpretation is based. To do this an analytical unit must be specified and it should be as small as possible. In other words, do not choose a movie or a group discussion but rather choose a scene, a statement, or an adjacent pair. The identification of the unit of analysis is in itself part of the process of interpretation.

The process of interpretation and analysis can never be fully formalized. It is above all a question of working step by step so that the process of interpretation can be made visible to both the researchers themselves and the reader.

Qualitative analysis is of necessity more personal and less standardized than statistical analysis. Thus, it is even more vital that the reader is given as exact a picture as possible of both the technical operations and the chain of reasoning that have led to the reported results. The reader must not be left at the mercy of the researcher's intuition alone. The demand for transparency in qualitative research is of crucial importance.

\section{Editors' and Referees' Assessment of Qualitative Research Reports}

A discussion of the evaluation criteria for peer review of qualitative research can start with evaluation principles for quasi-experimental research or natural experiments. The American Journal of Public Health published an evaluation system for these types of study (Des Jarlais, Lyles \& Crepaz, 2004) entitled TREND (Transparent Reporting of Evaluations with Nonrandomized Designs). TREND was designed specifically for research results in which the randomisation principle was somehow restricted. The criterion of transparency, which is central to this evaluation system, emphasises a detailed description of all steps and procedures, as well as a detailed justification of the choice and manner of application of the individual methods and theoretical background (see also Mayring, 1988, 1990).

Mareš (2002) analysed quality criteria for research using pictorial documents and summarised the findings with the concepts of completeness (how 
well the data capture the phenomenon examined), transparency (the accuracy, clarity, and completeness of the description of the individual phases of the study), reflexivity (the ability of researchers to reflect on their different steps and measures during the study and how the investigators may have influenced the research situation), and adequacy of interpretation and aggregation of contradictory interpretations (the identification and weighting of alternative interpretations and other validity-control techniques).

Des Jarlais, Lyles \& Crepaz (2004, pp. 363-365) have drawn up a 22-item list to serve as a general assessment guide for authors and evaluators. Box 8.2 shows some of their requirements and recommendations.

Additional recommendations proposed by Gilpatrick (1999) and Robson (2002) are summarized in Box 8.3.

a) An article should be provided with a structured abstract (as a minimum: background, aims, sample, methods, results).

b) The sampling should be described and justified, including an explanation of criteria used.

c) The theoretical background of the entire study, or individual methods, should be described, to show that the sample and data collection were consistent with the study's theoretical background.

d) The context (setting) in which the study was carried out should be described. The authors must describe the characteristics of the field in which the study was carried out, and what made it different from other settings.

e) A detailed description of the research intervention should be included, and of how study participants responded during that intervention.

f) A detailed description of the analytical methods applied, how they were used, including the tools used for minimising bias; and a validation of the results should be presented.

g) A description of the manner of data processing (e.g., technical aspects and procedures) is needed.

h) Description of outcomes and their interpretation are obviously necessary. This includes a discussion of limitations (contextual validity of results), and an analysis of how the design of the study reflects these limitations.

Box 8.2: Assessment Criteria for Qualitative Studies.

Source: Des Jarlais, Lyles \& Crepaz (2004). 
a) The research issue and the research questions and goals derived from it, should be properly presented.

b) The goals should be contextually embedded and put into a theoretical framework, with an analysis of the present state of knowledge.

c) The author should argue for the importance of their study against this background (e.g., what questions or issues the results should contribute to, how they will move the field forward).

d) Control tools (e.g., research logs, control points) should be reported and how ethical problems were handled (e.g., use of informed consents, careful adherence to research protocols, manner of preparing the research team to manage risky or problem situations).

Box 8.3: Evaluation Criteria for Qualitative Studies.

Sources: Gilpatrick (1999) and Robson (2002).

The qualitative paper, both in its entirety and in its constituent parts, will be evaluated by and large according to the same criteria and expectations as those applied to a quantitative report.

\section{Practical Advice for Writing a Publishable Qualitative Article}

A good way to start the process of improving both your writing skills and your chances of publication is to become familiar with the common reasons why editors reject qualitative articles (see Box 8.4), and then carefully read some examples of well-written qualitative articles (see Box 8.5).

Based on our experience as journal editors, referees, and researchers, we now present nine recommendations for potential authors of qualitative articles.

\section{Consider the Format and Structure of Your Article}

When you get acquainted with various addiction journals, you will realize that qualitative articles can look very different depending not only on their topic but also on where they are published. You can choose to target a specific journal and try to follow closely the format used in that publication. But if you want a greater choice of potential journals for your manuscript, and in particular if 
- The author has not related the study to earlier (international) literature.

- The research question is not clearly stated.

- The structure of the article is not clear or does not respond to the expected structure of articles in the journal.

- Theories, methods, and data analyses are not consistent.

- The central concepts are not clearly presented or used in a consistent way.

- The methodology is poor.

- The size of the data set is not defended in a convincing way.

- The data set is not sufficiently contextualised, or there is a clear selection bias.

- The data collection is poor and lacks validity control.

- The methods and analyses are not explained clearly enough, which may lead the referees and the editor to regard the article as too descriptive and the analyses based too much on intuition.

- The author makes unsound conclusions or unfounded generalisations.

- Ethical rules are violated or ethical issues are not mentioned or adequately discussed.

- The text is too long.

Box 8.4: Common reasons why editors decline qualitative articles. Source: Drisko (2005).

you are not a very experienced researcher, it may be wise to choose a traditional structure for your research report.

\section{Begin with the Abstract}

Most addiction journals require the authors to write very short abstracts, covering background, aims, data and methods, results, and discussion. It is a good idea for the author of a qualitative article to write a preliminary abstract at an early stage of the writing process to ensure that the text will be coherent and logical.

\section{Choose a Title that Corresponds to the Content}

The title of an article is very important. Drisko (2005) gives the following advice: present the research question reshaped into the manuscript title. 
Amos, A., Wiltshire, S., Bostock, Y., Haw, S., \& McNeill, A. (2004). 'You can't go without a fag . . . you need it for your hash' - a qualitative exploration of smoking, cannabis and young people. Addiction, 99(1), 77-81.

Demant, J., \& Järvinen. M. ( 2006): Constructing maturity through alcohol experience - Focus group interviews with teenagers. Addiction Research and Theory, 14(6), 589-602.

Herd, D. (2005). Changes in the prevalence of alcohol use in rap song lyrics, 1979-97. Addiction, 100(9), 1258-1269.

Maher, L., \& Hudson, S. L. (2007). Women in the drug economy: A metasynthesis of the qualitative literature. Journal of Drug Issues, 37(4), 805-826.*

Maeyer, J. D., Vanderplasshen, W., Camfield, L., Vanheule, S., Sabbe, B., \& Broekaert, E. (2011). A good quality of life under influence of methadone: A qualitative study among opioid-dependent individuals. International Journal of Nursing Studies, 48, 1244-1257.

Miovský, M. (2007). Changing patterns of drug use in the Czech Republic during the post-Communist era: A qualitative study. Journal of Drug Issues, 37(1), 73-102.

Phillips, D., Thomas, K., Cox, H., Ricciardelli, L. A., Ogle, J., Love, V., \& Steele A. (2007). Factors that influence women's disclosures of substance use during pregnancy: A qualitative study of ten midwives and ten pregnant women. Journal of Drug Issues, 37(2), 357-376.

Please visit the website of the International Society of Addiction Journal Editors (ISAJE) at www.isaje.net to access supplementary materials related to this chapter. Materials include additional reading, exercises, examples, PowerPoint presentations, videos, and e-learning lessons.

Box 8.5: Examples of well-written qualitative articles.

A title that indicates what you are interested in will generate more readers who really are interested in your research-and probably more citations of your article (see Chapter 10). Sometimes it is possible to formulate the title so that it also describes what kind of data you have used. A title should not promise too much or be too fancy. If the title of the article is "The commercial discourse on alcohol," the reader expects that the theoretical contribution will be substantial. If it is "An analysis of alcohol marketing" and you deal only with beer advertisements in a short period in Greece, the reader may be disappointed. 


\section{State the Research Question Early and Clearly}

It is a common failure in qualitative reports to embed the research question so deeply in the text that the reader cannot find it. The best way to avoid this is to include, at the beginning of your manuscript, a subtitle called "Research question" or "Aim of the study." An alternative is to present the question at the end of the background or introduction section.

It is not unusual for the reader of a qualitative article to find several different, sometimes even contradictory, research questions presented throughout the various sections of the article: one question in the introduction, another in the methods and data section, and a third in the discussion (Drisko,2005). Even if the research process in qualitative research is often more unpredictable than in quantitative research and you gain new insights during the research process that will affect your perspective, the aim of a research report is as a rule to report not on this exploratory process but instead on specific findings answering a specific question. The reader does not want to be taken through the whole story of the researcher's mistakes and new choice of questions. Focus on a single clear question that will orient the reader's interest and prepare him for the text to come. It may be that your research project will in fact be able to answer many questions. Perhaps then you should consider producing several shorter and focused articles, rather than trying to squeeze it all into one text.

If possible, phrase the research question in a way that reflects the scientific ambition of the study: Is it an article that explores a topic, aims at discovering a new social phenomenon, presents a new perspective, seeks to raise consciousness about a problem, evaluates a project, or tests a theory (Drisko, 2005)?

\section{Conduct a Thorough Review of Earlier Research}

A good review of earlier research on the topic is essential for your claim that you are contributing new knowledge. It also shows that you want to take your place in the research community and engage in serious dialogue with other researchers. If the referees find that you have overlooked important literature, particularly if it is their own work (and since qualitative addiction research is a small field, you will often have a referee that has contributed to your topic), or that you have misinterpreted earlier studies, they will read your study with skepticism. Do not limit yourself to literature from your own country, but be sure to cover what has been written from your own culture.

The literature review should not be solely descriptive. Use it to position yourself in relation to other researchers and to demonstrate that you are doing something new. What conclusions about your questions can already be drawn from earlier research? State why you think earlier studies have missed a particular aspect of the topic or have taken a perspective that can be complemented with 
a new one. Alternatively, say why and in what way you want to use an approach or develop a line of thought presented by someone else.

When you have presented a good review of earlier research, you will also have defended your theoretical and methodological position and your choice of data. Be certain to choose the right body of literature with theoretical relevance for your question. If you are studying gender differences in advertisements for tobacco, be sure to cover the literature on gender and media: do not focus exclusively on what we know about gender differences in smoking patterns.

A thorough review, in which you position yourself clearly, also offers a practical way to avoid unfavorable referees. If you state that you disagree with $\mathrm{X}$ who has not taken $\mathrm{Y}$ into account, the editor will probably not send your text to X, to avoid a conflict of interest. Since the number of possible referees available to the editor usually is limited, this is an important consideration.

\section{Present Enough Information in the Methods and Data Section}

According to Drisko (2005), inadequate methods are among the most common reason for qualitative articles being declined by editors. It is important to justify the choice of methods. If you want to be really convincing, explain your choice in relation to alternative methodologies. If you use several methods, explain how they complement each other. For instance, it is not enough simply to state that you use focus group interviews and a post-structuralist text analysis: You should describe how and why you use them

Remember that many readers of addiction journals will not be familiar with qualitative methods. Therefore, you must describe the content of the method quite explicitly. Show that the research methods are suitable for the purpose of the study. It is important to convince the reader that you have used your method(s) systematically and on the entire data set. This includes the consistent use of crucial concepts.

You must argue that the size of the sample is sufficient for your purpose. As noted above, a small sample is one of the factors that raises skepticism among readers of qualitative research. How extensive is your data set? How many interviews with how many persons? How many meetings or observations? Position the sample clearly but without being too wordy: Try to focus on the essential features that will help an uninitiated reader to understand what you are analyzing and what the sample represents.

It is important to explain why your data set is the most illustrative and useful to answer the question you are posing. Be careful to describe how you picked your sample. What criteria did you use? Can you compare the data set with other alternatives and why did you choose this one? Describe the important variations within the data set (e.g., age and gender distributions) so that the reader gets a good picture of it. If you have used only a part of the data you have collected within a project, describe the rest of the data briefly to illustrate the 
context or refer to another, already-published, article in which these data are presented.

For the interpretation and transparency of your reasoning, it is crucial to describe how the data were produced and collected and how these conditions may have influenced the data. What special conditions, for example, come into play if you collect data from A.A. members, for whom anonymity is important? Do they affect the research participants' willingness to be interviewed or how they talk during an interview? Tell the reader how (or whether) you presented the study to the participants. If you used focus groups, describe the groups' dynamics.

Describe carefully each step in the analysis so that the reader can accept your conclusions-or argue against them. A good rule is to present the analysis of one observation/item/response in detail. Describe your interpretations during the analysis in a systematic way and in small identifiable steps. Show the fruitfulness of your concepts. Show how you argued for saturation and how you handled diversity and contradictions in the data.

A thorough description of how the data were handled is also important. It should be clearly stated, for instance, how and whether the interviews were transcribed, coded, and grouped.

\section{Link the Results to the Research Question}

The presentation of the results is easiest for the reader to follow if the structure is directly linked to the research question, moves in logical steps according to the theory and method, and consistently uses the concepts presented earlier in the article.

Present your data in a systematic way in the body of the text, so that quotations, field notes, and other documentations are easily identifiable. The reader must be certain, for instance, whether you are using direct citations or analyzing interpretations of what the observed or interviewed persons said. The citations or other illustrations must be clearly contextualised. For observational material, state whether you collected the data yourself or if you used data collected by someone else.

Give enough raw data (e.g., direct citations) but not too much. Avoid very short quotations. If you run out of space, ask the editor if you can use online appendices for additional material. Do not refer in the results section to data that you have not already presented in the data and methods section; if you state that you are going to use interviews, do not refer to observations in the results section. If the results are contradictory, declare that fact openly and explain how this may have occurred and what it may mean.

If you use grounded theory, you should be able to present a theory as a result. Descriptive statements are not enough. The theory should be a product of the analyses and not just confirm or illustrate earlier theories (Glaser \& Strauss, 1967). 


\section{In the Discussion Section, Restate Your Main Findings and Relate Them to Earlier Research}

The structure of the discussion in a qualitative article can follow the same structure as in quantitative research reports. After a very short summary of your research question (check that it is the same as in the introduction) and the motivation for your wish to explore it, you can repeat in one sentence the main result of your study.

Following this, discuss how your findings relate to earlier research: Do they fill out the picture of what we already know or possibly challenge or even contradict earlier findings? In this section, you can also, if possible, refer to earlier quantitative research. In what way has your study been important for the research community or for a larger audience? Can the results change the picture of similar phenomena in other cultures? Discuss the extent to which the findings with this data set are relevant to the understanding of other situations. What are the concepts that can be transferred to other settings?

As noted in Chapter 12, a good discussion will also contain a consideration of the limitations of your study. What problems with the sample and data collection restrict the possibility of getting a full answer to your research question? With what other data could the answer have been more complete? Could you have used an additional or alternative method?

Finally, consider giving recommendations for further research that will improve knowledge about the topic you have studied.

\section{And Finally, Some General Advice}

First, it is sensible for qualitative as well as for quantitative researchers to save their good data for scientific articles. Many qualitative researchers publish their results as reports, sometimes in series that will have limited distribution, or as longer articles in monographs. If you want to spread your findings to a larger audience, it is often more efficient to publish one or more articles in a scientific journal.

Second, choose the right journal-a crucial success factor if you want to get your article published. The first step is to choose among either an addiction journal; a journal for qualitative research; or a scholarly journal for sociology, anthropology, history, etc. (see Chapter 3).

If you choose an addiction journal or a disciplinary journal, find out if it accepts qualitative reports. Table 8.1 presents a list of English-language addiction journals that publish qualitative research. Non-English-language journals as a rule accept submissions of qualitative articles. Check if the journal has particular demands on article length that will make it difficult for your submission to be accepted. Look at the editorial board anddetermine whether it includes members who are familiar with qualitative methods. Finally, look at the content 


\begin{tabular}{|l|l|}
\hline Addiction & International Journal of Drug Policy \\
\hline Addiction Research and Theory & Journal of Addictions Nursing \\
\hline Addictive Behaviors & Journal of Alcohol and Drug Education \\
\hline $\begin{array}{l}\text { African Journal of Drug and Alcohol } \\
\text { Studies }\end{array}$ & Journal of Drug Education \\
\hline Alcohol and Alcoholism & Journal of Drug Issues \\
\hline Alcohol Research and Health & Journal of Ethnicity in Substance Abuse \\
\hline Alcoholism Treatment Quarterly & Journal of Gambling Issues \\
\hline $\begin{array}{l}\text { American Journal of Drug and Alcohol } \\
\text { Abuse }\end{array}$ & Journal of Smoking Cessation \\
\hline Contemporary Drug Problems & $\begin{array}{l}\text { Journal of Social Work Practice in the } \\
\text { Addictions }\end{array}$ \\
\hline Drug and Alcohol Dependence & Journal of Studies on Alcohol and Drugs \\
\hline Drug and Alcohol Review & Journal of Substance Abuse Treatment \\
\hline Drugs: Education, Prevention and Policy & Journal of Substance Use \\
\hline & Nordic Studies on Alcohol and Drugs \\
\hline European Addiction Research & $\begin{array}{l}\text { Substance Abuse Treatment, Prevention, } \\
\text { and Policy }\end{array}$ \\
\hline Harm Reduction Journal & Substance Use and Misuse \\
\hline International Gambling Studies & Tobacco Control \\
\hline
\end{tabular}

Table 8.1: English-language journals that publish qualitative articles.

of the journal: To what extent do they publish qualitative articles? Bear in mind that many addiction journals are open to various research methods, even if those journals have a predominantly quantitative orientation.

Finally, consider if it would be good to suggest a suitable referee for your article. Some journal editors may find it difficult to identify experienced referees for your manuscript. As an author, you can always suggest someone whom you would like to review your text, without, of course, any guarantee that the editor will follow your advice.

\section{Conclusions}

In this chapter, we have emphasised that the similarities between conducting and writing up quantitative and qualitative research are greater than the differences. We have presented some quality criteria, particularly for qualitative research, discussed criteria for evaluation of journal articles, and given some practical advice to authors. 
Publishing qualitative research is as least as challenging as getting quantitative reports accepted. However, it is apparent that the addiction field as a whole is increasingly coming to realise the value of qualitative studies. We believe that, in the future, there will be an even greater interest in good qualitative research and a growing demand for mixed-methods studies. Those who have dug themselves down into the qualitative or quantitative trenches will emerge and start communicating with each other, for their own and everyone's mutual benefit.

\section{Acknowledgements}

The authors thank Tom Babor, Phil Lange, Tom McGovern, Peter Miller, Jean O'Reilly, and Betsy Thom for valuable comments on earlier versions of the text.

Please visit the website of the International Society of Addiction Journal Editors (ISAJE) at www.isaje.net to access supplementary materials related to this chapter. Materials include additional reading, exercises, examples, PowerPoint presentations, videos, and e-learning lessons.

\section{References}

Arminen, I. (1998). Therapeutic interaction. A study of mutual help in the meetings of Alcoholics Anonymous, Vol. 45. Helsinki: The Finnish Foundation for Alcohol Studies.

Creswell, J. W., \& Plano Clark, V. L. (2007). Designing and conducting mixed methods research. Thousand Oaks, CA: Sage.

Creswell, J. W., \& Tashakkori, A. (2007). Developing publishable mixed methods manuscripts. Journal of Mixed Methods Research, 2(1), 107-111.

Denzin, N. K., \& Lincoln, Y. S. (Eds.). (1998). The landscape of qualitative research: Theories and issues. Thousand Oaks, London, New Delhi: SAGE Publication.

Des Jarlais, D. C, Lyles, C., \& Crepaz, N. (2004). Improving the reporting quality of nonrandomized evaluations of behavioral and public health interventions: The TREND statement. American Journal of Public Health, 3(94), $361-366$.

Drisko, J. (2005). Writing up qualitative research. Families in Society: The Journal of Contemporary Social Services, 86(4), 589-593.

Gilpatrick, E. (1999). Quality improvement projects in health care. London, Thousand Oaks, New Delhi: SAGE Publications. 
Glaser, B. G., \& Strauss, A. L. (1967). The discovery of grounded theory: Strategies for qualitative research. New York: Aldine.

Lalander, P. (2003). Hooked on heroin: Drugs and drifters in a globalized world. London/New York: Berg Publisher.

Mareš, J. (Ed.). (2002). Sociální opora u dětí a dospívajících II [Social support of children and adolescents]. Hradec Králové: Nukleus.

Mayring, P. (1988). Qualitative inhaltsanalyse: Grundlagen and techniken. Weinheim: Deutcher Studien Verlag.

Mayring, P. (1990). Einführung in die qualitative socialforschung. München: Psychologie Verlag Union.

Miovský, M. (2006). Kvalitativní prístup a metody v psychologickém výzkumu [Qualitative approach and methods in psychological research]. Praha: Grada Publishing.

Miovský, M. (2007). Changing patterns of drug use in the Czech Republic during the post-Communist era: A qualitative study. Journal of Drug Issues, 37(1), 73-102.

Miovský, M., \& Zábranský, T. (2003). Kvalitativní analýza dopadu nové drogové legislativy na drogovou scénu z perspektivy pracovníků zdravotnických zařízení a významných poskytovatelů služeb uživatelům nelegálních drog [Impact of new drug legislation on drug scene from the perspective of health care professionals working with drug users: Qualitative analysis]. Čs. psychologie, 47(4), 289-300.

Patton, M. Q. (1990). Qualitative evaluation and research methods. London, Thousand Oaks, New Delhi: SAGE Publications.

Robson, C. (2002). Real world research. Oxford: Blackwell Publishing.

Stimson, G. V., Fitch, C., Des Jarlais, D., Poznyak, V., Perlis, T., Oppenheimer, E., Rhodes, T., \& for The Who Phase II Drug Injection Collaborative Study Group. (2006). Rapid assessment and response studies of injection drug use. Knowledge gain, capacity building, and intervention development in a multisite study. American Journal of Public Health, 96(2), 288-295.

Strauss, A., \& Corbin, J. (1998). Basics of qualitative research: Techniques and procedures for developing grounded theory, Second Edition. Thousand Oaks, CA: SAGE Publications.

Sulkunen, P. (1987). Sosiologian avaimet [The keys to sociology]. Porvoo, Helsinki, Juva: WSOY.

Whittemore, R., Chase, S. K., \& Mandle, C. L. (2001). Validity in qualitative research. Qualitative Health Research, 4(11), 522-537. 